\title{
The Application of the Third Party's Right Relief System in Civil Procedure Law of the People's Republic of China
}

\author{
Haitao Chen ${ }^{1}$ \\ ${ }^{1}$ Faculty of law, Beijing Normal University, Beijing, China \\ Correspondence: Haitao Chen, No.19, Xinjiekouwai St, Haidian District, Beijing, 100875, China. E-mail: \\ chen_ocean@qq.com
}

Received: September 18, 2020

Accepted: November 3, 2020

Online Published: November 25, 2020

doi:10.5539/jpl.v14n1p43

URL: https://doi.org/10.5539/jpl.v14n1p43

\begin{abstract}
With the continuous revision and improvement of the Civil Procedure Law and relevant judicial interpretations, China has formed a complete system to protect the rights and interests of the third party not involved in the original trial, including enforcement objection, execution objection lawsuit, the third party revocation lawsuit and retrial procedure. However, at present, the legal provisions on the cis-position of application of the above procedures are still vague. In order to explain and solve this problem more clearly, this thesis divides the time after the judgment is made into three stages - "from the time when the judgment is made to before the judgment takes effect", "the stage of execution" and "after the stage of execution". Based on the characteristics and purposes of each procedure and the functional characteristics of judicial organs, the cis-position of each procedure in different stages is determined reasonably.
\end{abstract}

Keywords: the third party revocation lawsuit, objection to enforcement, lawsuit of the enforcement, retrial

\section{The Development Stages and Problems of the Third Party Relief System}

Generally speaking, the development of the third party's right relief system in China has experienced three stages.

\subsection{Embryonic Stage}

The first stage started with the promulgation of the Civil Procedure Law of the people's Republic of China (hereinafter referred to as the Civil Procedure Law) by the National People's Congress in 1982 and ended with the Civil Procedure Law of the people's Republic of China (for officially implemented) in 1991. It is the embryonic stage of the third party's right relief system in China. In this stage, the third party is divided into two types: the third party with independent claim right and the third party without independent claim right, and the relief procedure of the third party not involved in the original trial (objection to enforcement) is established for the first time. However, this provision is only effective for the third party with independent claim right, not for the third party without independent claim right. What's worse, this provision does not provide for the relief when the rights of the third party not involved in the original trial are damaged during the two periods of "after the judgment takes effect and before the execution stage" and "after the execution of the judgment". After that, the Supreme People's court has made it clear that the third party with independent claim right has the right to choose the third party with independent claim right to participate in the lawsuit, or bring a lawsuit to another court with jurisdiction as plaintiff. It strengthens the right relief of the third party who has the independent claim right.

\subsection{Development Stage}

The second stage is the development stage of China's third party relief system from the formal formulation of the Civil Procedure Law (for officially implemented in 1991) to the revision of the Civil Procedure Law (revised in 2012). At this stage, the litigation status of the third party is gradually clear, and the protection and relief mechanism for the third party is gradually improved. In this stage, by amending the Civil Procedure Law and promulgating a new judicial interpretation, the third party without independent right who bears civil liability has the right to appeal for the first time. On the other hand, the system of action against execution objection is allowed, and a new way for protecting the third party - the retrial procedure is also added. However, there is no provision for the relief procedure of the third party not involved in the original trial, so in the judicial practice, it is mainly solved by way of complaint. That is to say, the third party not involved in the original trial appeals to the court, and the court starts the retrial procedure according to its functions and powers, or appeals to the procuratorate 
office, and the procuratorate office lodges a protest, or appeals to other organs, then, the appeal is transferred to the court, the court starts the retrial procedure under the supervision of the organ. Until 2008, the procedure of the third party applying for retrial was established, and the difficulty of the third party applying for retrial was finally solved.

\subsection{Stage of Perfection}

The third stage is from the revision of the Civil Procedure Law (revised in 2012) to today, which is the improvement stage of the third party relief system in China. At this stage, the most important point is that the revised Civil Procedure Law learns from the experience of France and adds the third party revocation system as a new way to protect the rights of the third party. Generally speaking, the res judicata of a judgment is relative, which only binds the parties, but it will break through the limitation of relativity in certain circumstances and act on the third party. This means that some third parties who are not party to the case may also accept the binding force of the judgment without participating in the trial. This is unfair to the third party outside the case, and relief measures must be provided for them. Therefore, the Civil Procedure Law stipulates that if a third party fails to participate in the proceedings due to reasons that cannot be attributed to him, but there is evidence to prove that some or all of the contents of the legally effective judgment, ruling or mediation statement are wrong and damage their civil rights and interests, they may bring a lawsuit to the people's court within six months from the date when they know or should know that their civil rights and interests have been damaged.

\subsection{Problems of the Third Party Relief System}

According to what has been mentioned above, so far, we can find that the objection to execution, the lawsuit of execution, the third party revocation lawsuit and the application for retrial system together constitute the right relief system for the third party in China's civil procedure litigation. However, through our careful observation, we can find that there is no detailed arrangement in the relevant laws of China on how to determine the order of application of the above-mentioned various relief procedures for the rights of the third party, and how to coordinate them when they conflict. This is also the focus of this article. In order to illustrate this problem in a better way, the following will be divided into three stages: "after the judgment takes effect to the execution ", "the implementation " and "after the implementation".

\section{The Relief of the Third Party's Rights in the Period "After the Judgment Takes Effect to the Execution"}

There are four kinds of right relief procedures for the third party in the period: first, the third party's revocation; second, the application for retrial by the outsider; third, the court starts the retrial according to its authority; fourth, the procuratorial supervision (including procuratorial suggestions and civil protest). Based on the main body of the initiation procedure, the above-mentioned four relief procedures can be divided into two categories: on the one hand, the relief procedure is initiated by the third party not involved in the original trial, including the third party's revocation and the third party's application for retrial procedure; on the other hand, the judicial organ initiatively starts the relief procedure for the third party according to its authority, including the court starts the retrial according to its authority and the procuratorial supervision. However, due to the lack of enthusiasm of the court and the procuratorate, and the conditions for the court initiating a retrial according to its authority or the procuratorate raising a procuratorial proposal or protest are more stringent, these two ways are rarely used in practice. At this stage, the third party not involved in the original trial obtains the right relief mainly through the way of application by himself. So, the focus of the content of this part is on the cis-position between the suit of the third party discharging the judgement and the third party's application for retrial, and the cis-position between the suit of the third party discharging the judgement and the judicial organs (courts and procuratorates) starting relief procedures according to their functions and powers.

\subsection{The Cis-Position between the Third Party's Revocation and the Third Party's Application for Retrial}

On this issue, in the legislative process of the suit of the third party discharging the judgement, there was a heated discussion among scholars who have diffident opinions. One view, for example professor ZhuJingao, is that the legislative purpose of the third party's revocation of litigation is to protect the third party from the damage of litigation delay when they encounter false litigation. And it can replace the system of applying for retrial by the third party. Another point of view is that there are many differences between the system of the third party's revocation and the system of application for retrial by an outsider. For example, in the purpose of litigation, the qualification of the subject, the effectiveness of the judgment and so on. Professor Zhang Weiping from Tsinghua University is a strong supporter of this view. Therefore, the scope of application of the two standards is absolutely different. There is also a new view that the suit of the third party discharging the judgement can be prescribed as a special procedure under the retrial system, and some procedural provisions of the Civil Procedure Law on the retrial system can be applied. From my view, before studying the sequence of the above procedures, we should 
first make clear the similarities and differences between the two procedures.

From their similarities, both of them, as the relief procedures after the judgment of the third party's rights and interests, have impacted the judgment effectiveness to a certain degree, and have damaged the stability of civil rights and obligations between the parties and others, and even the authority and efficiency of judicial procedures. According to articles 301, 302 of Judicial interpretation of the Civil Procedure Law (formulated in 2015), the third party can choose to use these two kinds of relief methods at the same time or successively.

From their differences, there are many differences in the subject, the basis and the legal effect of the initiation procedure. Firstly, the startup program is different. Base on the experience of other countries (such as France and Japan) and the legal provisions of China, the subject applying for starting the retrial procedure includes all the outsiders whose entity rights and procedural rights are damaged by the original judgment. The subject applying for the third party cancellation lawsuit only includes the third party with independent claim right and the third party without independent claim right. Secondly, the basis for starting the procedure are different. The legal basis of applying for retrial is mainly articles 200, 201, 202 of the Civil Procedure Law (revised in 2012) and relevant judicial interpretations. These laws and judicial interpretations clearly stipulate the reasons and the conditions for applying for retrial, for example, the application for retrial by a third party outside the case must be restricted by the condition that "no new lawsuit can be filed". Meanwhile, the basis of initiating the third party's rescission action is that the third party's rights and interests are damaged due to the fact that he or she fails to participate in the litigation due to the reasons that cannot be attributed to him. It focuses on protecting the substantive rights and interests of the third party and preventing the "malicious litigation" under the regulation of the debate principle to bring irreparable damage to the substantive rights of the third party not involved in the original trial. Thirdly, the legal effects are different. The retrial instrument is a comprehensive trial of the previous action. The object of the third party's rescission action is limited to the claim of the outsider, which is generally the disadvantageous part of the previous judgment to the third party. The scope of the court's hearing should not exceed the scope of the claim filed by a third party outside the case.

Combined with the legal provisions and the characteristics of the above two relief procedures, we can find that the law gives the third party the most comprehensive right protection, so that the third party can bring the suit of the third party discharging the judgement and retrial at the same time under certain circumstances. But we should also pay attention to the interests of the plaintiff and the defendant, the interests of the third party and judicial efficiency, and seek a balance point. Based on the principle of post application of special relief mechanism and the most miscellaneous nature of retrial, I advice, during the period before the execution stage after the judgment takes effect, the third party's cancellation action should be applied in priority for the protection of the interests of the third party, and only when the outsider is unable to bring any other lawsuit that does not endanger the res judicata, it can be allowed to file a retrial.

\subsection{The Cis-Position between the Suit of the Third Party Discharging the Judgement and the Court Starts the Retrial According to Its Authority}

Many domestic scholars believe that the power of the court to initiate retrial according to its authority should be abolished, because it violates the neutral principle of court judgment and interferes with the parties' right of disposition excessively. However, it is still retained after the amendment of the Civil Procedure Law. In this case, we still need to discuss the cis-position between the suit of the third party discharging the judgement and the court starts the retrial according to its authority carefully. The conditions for the court to initiate the retrial on its own initiative are more stringent than those for the third party to apply for the court to start the retrial on its own initiative. Unless there are significant procedural or substantive defects (for example, the judge did not withdraw, or the judgment applied the law wrongly) in the judgment, ruling and mediation statement of the original trial, and there is clear evidence to prove it, the court can initiate the retrial on its own initiative. Therefore, when there is a conflict between the suit of the third party discharging the judgement and the court's initiation of retrial on its own authority, the third party's revocation procedure should be the first choice. It is more convenient and effective to apply priority to the third party's rescission action. This is also the best way to maintain the neutrality of the court.

\subsection{The Cis-Position between the Suit of the Third Party Discharging the Judgement and Procuratorial Supervision}

According to articles 208 of the Civil Procedure Law (revised in 2017), there are two types of inspection and supervision. One is that the higher procuratorate can protest against the legally effective judgment, ruling and mediation statement of the lower court. The second is that the procuratorates can put forward procuratorial suggestions on the legally effective judgments, rulings, mediation documents or trial supervision procedures of the courts at the same level, and the procuratorates can also put forward procuratorial suggestions for the illegal acts of judges in other judicial procedures. Then report these to the higher-level procuratorate for record. The article 39 
of Rules for the Supervision over Civil Proceedings by the People's Procuratorates (for Trial Implementation) specifies the circumstances in which a third party outside the case applies to the procuratorate for inspection and supervision: citizens, legal persons and other organizations hold that the judicial personnel in the civil trial procedure of the people's court have committed illegal acts, or the civil execution activities have violated the law. The article 41 of Rules for the Supervision over Civil Proceedings by the People's Procuratorates (for Trial Implementation) stipulates three situations for the procuratorate to start inspection and supervision according to its functions and powers: first, it damages the national interests or social and public interests; second, the trial and execution personnel have corruption, bribery, favoritism, bending the law and other acts; third, other circumstances that require the people's procuratorate to follow up and supervise in accordance with the relevant provisions. It can be seen that during this period, the party concerned can choose the third party to cancel the lawsuit or to inspect and supervise to protect their own rights and interests. For the cis-position of the two procedures, I suggest, the third party should give priority to the application of the third party's revocation suit. Only when the third party's cancellation action is not enough to remedy the rights of the third party, can we apply for procuratorial supervision and relieve our own rights through the Procuratorate's protest or procuratorial suggestions.

\section{The Relief of the Third Party's Rights in the Period "The Implementation"}

Execution relief refers to the relief method and system stipulated by law in order to protect the legitimate rights and interests of the parties and the third party when the interests of the parties or interested parties are infringed upon due to the illegal or improper enforcement of the court. According to articles 227 of the Civil Procedure Law (revised in 2012), an outsider can raise a written objection to the object of execution in the execution stage, which is the system of objection to execution in China. After hearing the case, the court may make a ruling on the objection to execution made by an outsider. If an outsider in the case refuses to accept the court's ruling and is related to the error of the original judgment or ruling, the outsider may handle the matter in accordance with the procedure of trial supervision; if it is irrelevant to the original judgment or ruling, the outsider may bring a lawsuit to the people's court within 15 days from the date of service of the ruling. The latter is called the action system of objection to execution. Some scholars think that the objection to execution can only be regarded as a pre procedure of the third party relief procedure, because it does not necessarily lead to the occurrence of relief procedure, nor does it necessarily restrict and correct the damage of the third party's rights and interests caused by the enforcement action. However, I think, the objection to execution can, in principle, lead to the suspension of execution and prevent the damage from further expanding, which is already a relief to the third party.

At the same time, it should be emphasized that the action of objection to execution is aimed at the substantive matters of the subject matter of execution which have nothing to do with the original judgment and ruling; the third party should take the application for enforcement objection as the premise, in other words, after the objection is rejected by the court, the third party can further bring the action of objection to execution against the substantive matters which have nothing to do with the original judgment and ruling; in the execution stage, the outsider's application for retrial aims at the substantive matters related to the original judgment and ruling, and should also take the execution objection procedure as the pre procedure, that is, only after the objection to execution filed in advance is rejected by the court, can the outsider file a retrial for the substantive matters related to the original judgment and ruling. In addition to the above-mentioned objection to execution, the action of objection to execution, and the application for retrial by an outsider in the execution stage, the third-party relief methods also include the following: first, the third party's action of revocation; Second, the retrial procedure, including the application for retrial by an outsider, the retrial initiated by the court in accordance with its authority and the procuratorate's proposal or protest.

\subsection{The Cis-Position between the Execution Objection and the Execution Objection Lawsuit}

In the Civil Procedure Law of the People's Republic of China, legal provisions on objection to execution and action of objection to execution are not consistent with those of traditional civil law countries. Generally speaking, other countries or regions in the civil law system generally limit the scope of application of objection to enforcement to cases where the enforcement method or procedure is illegal, and the scope of application of the action of objection to enforcement is limited to the case where the substantive right of the outsider is infringed. But according to the relevant provisions of the Civil Procedure Law, the reasons why the outsider raises objection to execution include illegal execution or illegal execution procedure, as well as disputes over the substantive right of the subject matter of execution. The dispute over the substantive rights which have nothing to do with the original effective judgment is the reason why the outsider brings the action of objection to execution.

According to the above analysis, in theory, when an outsider disputes the substantive rights unrelated to the original judgment, he can choose to implement objection or execution objection lawsuit to protect his own rights. However, 
according to the legal provisions and the specific application of the court in the judicial practice, it is generally regarded as the precondition for the outsider to raise the lawsuit of the enforcement. In addition, the lawsuit of the enforcement will not produce the effect of suspension of execution in principle, on the contrary, the action of objection to enforcement will produce the effect of suspending execution in principle. The deep reason for this phenomenon is that the concept of procedural legitimacy is not established, according to the basic theory of civil procedure, the substantive matters should be solved through litigation procedure. In the long run, we should learn from the common practice of civil law countries represented by the French Civil Procedure Law. The illegal procedure or execution method that does not involve substantive rights should be solved by objection to execution, while the matters involving substantive rights should be solved through litigation based on the basic requirements of civil litigation and the basic nature of litigation. The conflict and negative consequences between the two systems can be avoided if the objection to enforcement is regarded as a temporary measure similar to the suspension order in the civil law system, and the objection action is positioned as the litigation procedure for the final revocation of the relevant enforcement measures. But right now, when the outsider of the case is confronted with the conflict between the use order of the execution objection and the execution objection lawsuit, the execution objection should still be applied preferentially. As to whether it is necessary to further choose to file an action of objection to execution, the court's specific ruling results should be taken into consideration.

\subsection{The Cis-Position between the Execution Objection Lawsuit and the Third Party Cancellation Lawsuit}

As for the relationship between the two procedures, some scholars in Taiwan region, such as Xu Shihuan and Wu Congzhou, believe that if the third party not involved in the original trial has the opportunity to file an action of objection to execution, the third party's cancellation action is not allowed. These two kinds of relief procedures can not be initiated at the same time, nor can they be filed again after the appeal of objection to execution is over. If the third party has already filed the action of rescission, the action of objection to execution can not be brought at the same time, and it is not allowed to bring the action of objection to execution by the outsider after the termination of the action. However, to determine the relationship between the two procedures, we can not only rely on one's own opinion, but should be based on careful analysis to make a correct judgment.

Firstly, the purposes of the two procedures are different. The third party's cancellation of litigation procedure is mainly to prevent the false litigation behavior that infringes the interests of the third party not involved in the original trial and provides a relief procedure for the third party out of the case who has not participated in the proceedings to obtain procedural protection. The action of objection to execution is aimed at the related rights of the subject matter of execution. The subject matter of execution includes "the ownership of the subject matter of execution" and "other rights to prevent the transfer or delivery of the subject matter", such as the right to use the residential base, the right to contract for operation, and so on. It is a relief procedure to protect the parties and the third party not involved in the original trial from the illegal or improper infringement of the court's enforcement act. Secondly, the time of application of the two procedures is different. The third party's action of rescission can be brought at any stage after the judgment takes effect, but there is also a restriction that "the third party can or should know that his civil rights and interests are damaged within six months". The action of objection to execution can only be brought in the execution stage. Thirdly, the most important point is that the legal effects of the two procedures are different. The third party's cancellation action can not only solve the rights and obligations relationship between the third party and the original litigant, but also may redefine the relationship between the original litigation parties. The legal effect of the action of objection to execution is limited to the exclusion of the execution of the specific object, and does not solve and determine the relationship between the rights and obligations of the original litigation parties.

Obviously, compare the ratio of the third party's rescission action to the action of objection to execution, the former has a wider and more profound impact on legal relations. As a conventional remedy for the third party not involved in the original trial, the action of objection to execution is more convenient and more conducive to the stability of the legal judgment, so it should be used preferentially. As an unconventional means of relieving the third party in the execution stage, the action of rescission has the characteristics of breaking the res judicata of the original judgment and its own particularity. We should put it in a backward position. In other words, if an outsider can protect his rights through the action of objection to execution, he should give priority to the lawsuit of objection to execution.

\subsection{The Cis-Position between the Third Party Cancellation Lawsuit and the Application for Retrial System}

According to the Article 303 of Judicial interpretation of Civil Procedure Law (formulated in 2015), "Where, after a third party initiates a revocation action, the enforcement of the effective original judgment, ruling or consent judgment fails to be suspended, the enforcement court shall examine the enforcement objection raised by the third 
party in accordance with the provisions of Article 227 of the Civil Procedure Law. Where the third party refuses to accept the ruling on rejection of enforcement objection, and files a retrial petition for trial of the original judgment, ruling or consent judgment, the people's court shall not accept such petition. Where any party not involved in this case refuses to accept the people's court's ruling on rejection of its enforcement objection, deeming that the original judgment, ruling or consent judgment damage has damaged his or its legitimate rights and interests, he or it shall file a retrial petition in accordance with the provisions of Article 127 of the Civil Procedure Law. Where a third-party revocation action is initiated, the people's court shall not accept such action." In the implementation stage, the following two kinds of relief paths are not feasible: "the third party's action for revocation - objection to execution - application for retrial by the third party" and "objection to execution application for retrial by the third party - suit for revocation by the third party". That is to say, if the third party does not bring the third party's cancellation action at this stage which is after the judgment takes effect and before the execution of the procedure, the execution objection should be applied preferentially in the execution stage. Only in the condition that the objection to execution is rejected, the third party not involved in the original trial can consider to file an action of objection to execution, a suit of revocation by the third party or retrial according to the situation. Moreover, if the third party brings a suit for revocation and applies for retrial at the same time, in principle, the action of the third party's cancellation should be incorporated into the retrial procedure, except for the cases of malicious collusion and intentional damage to the rights of the third party.

\subsection{The Cis-Position between the Third Party Cancellation Lawsuit and the Civil Procuratorial Supervision}

The civil procuratorial supervision should not only examine whether the civil enforcement acts violate the enforcement procedures, but also examine whether the enforcement actions have caused damage to the national interests, social interests and the legitimate rights and interests of others. The suit of the third party discharging the judgement is to protect the interests of the third party not involved in the original trial. In theory, only when the court's judgment or ruling is obviously wrong and the legitimate rights and interests of the third party are affected, the protection of the third party's rights by the civil procuratorial supervision and the suit of the third party discharging the judgement will be crossed. The starting mode of procuratorial supervision can be divided into two kinds of situations, starting according to the application of the parties or outsiders and starting according to the authority of the procuratorate.

According to the article 33 of Rules for the Supervision over Civil Proceedings (for Trial Implementation in 2013) if a party applies for inspection and supervision, the procuratorate shall not accept it in the following three cases: firstly, the third party has not applied to the court for retrial or the time limit for applying for retrial has expired; secondly, the third party has the opportunity to appeal but not appeal; thirdly, the law stipulates that the third party not involved in the original trial can take the initiative to seek relief from the court, while the third party not involved in the original trial chooses to give up seeking relief from the court. That is to say, the party or the outsider should exhaust other relief means to start inspection and supervision through application. Furthermore, the parties or the outsider should protect their rights through the way of initiating the third party's cancellation lawsuit before starting inspection and supervision through application. According to the article 41 of Rules for the Supervision over Civil Proceedings (for Trial Implementation in 2013) there are three situations in which the people's procuratorate should take the initiative to supervise in accordance with its functions and powers. Firstly, it has damaged national interests or public interests; Secondly, any judge or any of the enforcement personnel has committed an illegal act such as committing embezzlement, accepting bribes, practicing favoritism, or adjudicating by bending the law; thirdly, the people's procuratorate is required by the relevant provisions to follow and supervise the handling of the case. In this case, there will be no conflict between the third revocation litigation system and the inspection and supervision system.

\section{The Relief of the Third Party's Rights in the Period "After the Implementation"}

In the two stages of "after the judgment takes effect, before the execution stage" and "the implementation stage", the measures to protect the rights of the third party not involved in the original trial have been very comprehensive. If the outsider knows that in the first two stages, he can protect the right of himself by starting corresponding procedures or systems, but he fails to seek judicial relief in time, after the execution stage, the exercise of his rights should be restricted. Because this will cause the legal relationship between the parties in the original lawsuit to become unstable again, and also increase the cost of the court operation, and there is the suspicion of abuse of judicial rights by outsiders. If the third party not involved in the original trial does not exercise his right in time, he may not bring a suit for revocation by the third party after the execution stage. However, it is still necessary to leave relief channels for the third party not involved in the original trial, and the method for reference is to allow the third party not involved in the original trial to file a lawsuit for restitution of unjust enrichment to the executor. In addition, considering the retrial procedure as an unconventional relief means, it has the function of covering the 
bottom. If the original judgment is wrong or the judicial personnel violate the law, the retrial procedure can still be initiated according to the application of the parties or by the judicial organs (courts and procuratorates). In a word, the third party not involved in the original trial should take their rights in time to protect their rights from the infringement of the original litigants.

\section{References}

Fu, G. Y. (2013). Some focal issues of civil procuratorial supervision - taking the revised Civil Procedure Law as the object. Research on Rule of Law, (9), 47.

Jiang, W. (2013). Civil Procedure Law (6th ed.). BeiJing, China: Press of Renmin University of China.

Li, W. G., \&Wu, F. Y. (2017). On the applicable relationship between the action of the third party's revocation and the application for retrial by an outsider. Hubei Social Sciences, (5), 144-149.

Liu, D. (2020). A study on the procedural rules of absorbing the third party's revocation in retrial. The Jurist, (2), 149-159.

Wang, F. H. (2013). On the application of the suit of the third party discharging the judgement. Tsinghua University Law Journal, (4), 53.

Wang, Y. X. (2012, September 26). The interpretation and application of the third party revocation system. People's Court Daily, pp. A7.

Zhang, W. P. (2009). A lawsuit of dissent from an outsider. Chinese Journal of Law, (1), 6.

Zhang, W. P. (2020). The structural adjustment and reconstruction of the third party system in China's civil litigation. Contemporary Law Review, (4), 80-93.

Zhang, W. P., \& Li, H. (2012). Principle and application of new Civil Procedure Law. BeiJing, China: The People's Court Press.

Zhang, W. P., \& Ren, Z. (2014). Research on the procedural protection system of the rights and interests of the third party not involved in the original trial. Science of Law, (6), 138.

Zhang, X. M. (2018). On the "mission" of the suit of the third party discharging the judgement. Law and Social Development, (4), 140-154.

Zhou, K. W. (2020). Clarify the relationship between the third party's rescission action and the application for retrial by the outsider. Journal of Law Application, (9), 99-105.

Zhu, J. G. (2017). Objection to the suit of the third party discharging the judgement. Journal of Political Science and Law, (5), 90-100.

\section{Copyrights}

Copyright for this article is retained by the author(s), with first publication rights granted to the journal.

This is an open-access article distributed under the terms and conditions of the Creative Commons Attribution license (http://creativecommons.org/licenses/by/4.0/). 